\title{
Behavioral hypotheses and choice reaction time'
}

\author{
IRA H. BERNSTEIN AND CHARLES REESE
}

ARLINGTON STATE COLLEGE

\begin{abstract}
Abstraet
Three trained Ss participated in a choice reaction time task under conditions of $0,1,2$ and 3-bits of stimulus uncertainty. Stimuli were presented in random sequence. Prior to each presentation Ss were required to state a behavioral hypothesis, i.e., guess which stimulus event would occur. The stimulus uncertainty-choice reaction time relationship was linear, confirming previous findings. However, when correct and incorrect behavioral hypothesis trials were separately analyzed, it was found that the positive linear relation was obtained only in the latter case; choice reaction time was independent of stimulus uncertainty when S's guess was correct.
\end{abstract}

\section{Problem}

Choice reaction time (CRT) for information-conserving visual-motor pairings is linearly related to stimulus uncertainty (SU) when a low error rate is maintained (Hyman, 1953; Brainard, Irby, Fitts \& Alluisi, 1962; Posner, 1964). Various mechanisms have been proposed to account for this relationship. The present study utilized an approach found fruitful in the study of verbal behavior (Dulany, 1962) which stresses the role of self-instructional sets and the inference of these sets through verbal reports. Ss were asked to guess which stimulus event would occur on a given trial although they were informed that the stimulus sequence was random. These guesses were designated as behavioral hypotheses (BH). The SU-CRT relationship was examined separately for $\operatorname{correct}(\mathrm{BH}+)$ and incorrect $(\mathrm{BH}-)$ guesses to see what functional relationships exist among $\mathrm{SU}, \mathrm{BH}$ and $\mathrm{CRT}$.

\section{Method}

Subjects: Three senior undergraduate psychology majors, two male and one female, served as paid Ss for two 1-hr. practice sessions and eight 1-hr. experimental sessions. A fourth female $\mathrm{S}$ was run but discarded because of progressively poor motivation and variable performance.

Apparatus: A specially constructed visual display and response unit was utilized consisting of eight neon NE-51 glow lamps and four double throw PBX telephone switches. The glow lamps were arranged in two bilaterally symmetrical 2-in square patterns separated from one another by $5-1 / 2$ in. The response switches were located underneath these patterns. CRTs were measured by a standard Lafayette $.01 \mathrm{sec}$. electric timer. The constant $1.5 \mathrm{sec}$. delay period was timed by a Hunter timer.

Procedure: Each $\mathrm{S}$ responded in a $0,1,2$ and 3-bit SU condition produced by varying the number of equiprobable stimulus alternatives. In each of these conditions, stimuli appeared randomly among the eight positions. However, information supplied by $\mathrm{E}$ as to which pattern (left and right) and/or which position within a pattern (top left, top right, etc.) would be relevant for that trial reduced SU appropriately.

The two practice sessions each consisted of 128 3-bit and 1280 -bit trials. In the succeeding eight sessions, a total of 384 CRTs were obtained within each SU condition for each $S$ through presentation of three 16-trial blocks per session per condition. Trial block order was randomized across Ss and across sessions. BH reports were obtained on all 1,2 and 3-bit trials. Thirty-two 0-bit and 32 3-bit warm-up trials were run at the start of each experimental session. Trials producing latencies of $1 \mathrm{sec}$. or longer were excluded from the analyses. It was noted that on virtually all of these trials Ss responded correctly but missed the appropriate response switch. As the number of trials excluded on this basis was less than $2 \%$, this seemed a more desirable procedure than artifactually inflating the obtained means through inclusion of these trials.

\section{Results}

The SU-CRT relationship for all trials and as a function of $\mathrm{BH}(+$ or - ) is presented in Fig. 1. The composite reflects trends found in each $\mathrm{S}$; hence, the individual data is not shown. Considering all trials, the trend is linear, replicating previous findings. Simple analyses of variance, conducted separately for each $\mathrm{S}$ across the four SU conditions, confirmed this impression: Values of $\mathrm{F}$ ranged from 164.26 to 401.01 $(p<.001$ in all cases). The linear trend accounted for $95 \%, 98 \%$ and $99 \%$ of the between-conditions variation for the three Ss.

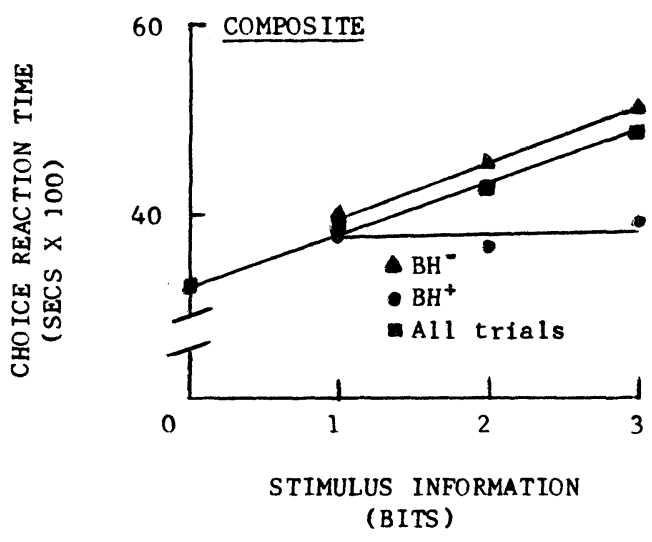

Fig. 1. Choice reaction time (CRT) as a function of stimulus uncertainty (SU) for all trials, BH + trials, and BH - trials. 
Figure 1 also indicates that this degradation with increasing $\mathrm{SU}$ is limited to the $\mathrm{BH}$ - trials. The $\mathrm{BH}$ data were analyzed as a nested two-factor design (BH and levels of $\mathrm{SU}$ within $\mathrm{BH}$ ), separately for each $\mathrm{S}$. On BH- trials, CRTs differed significantly across conditions with values of $\mathrm{F}$ ranging from 77.67 to 191.97 ( $p<.001$ in all cases). The linear component of this effect accounted for $98 \%, 98 \%$ and $99 \%$ of the betweenconditions variation. However, on $\mathrm{BH}+$ trials, SU produced significant differences only in the case of one $\mathrm{S}$ $(p<.05)$. Finally, overall differences among BH conditions were highly significant, with values of $\mathrm{F}$ ranging from 124.48 to 566.96 ( $p<.001$ in all cases).

\section{Diseussion}

One possible interpretation of the present results is in terms of a response conflict theory. This attributes SU-produced CRT degradation to the increase in the number of possible responses that can occur on a given trial. Response conflict is generally assumed to be a function of the relative strengths of the competing responses as well as their number (Berlyne,1957). The present findings suggest that certain responses are primed to minimize response conflict.

However, these results are also interpretable in terms of a stimulus selection rather than a response selection position. Adams (1962) has recently discussed an expectancy model which he has utilized in temporal as well as event (stimulus) uncertainty tasks. The present results confirm his impression that performance is at a maximum when expected events, defined by the BH process, occur. Similarly, filter theory (Broadbent, 1957) seems to bear equivalent relevance. In filter theory terminology, each possible event would be represented by a channel. To prevent jamming of imputs, biases are assumed operative to favor messages (events) entering one selected channel. If $\mathrm{BH}$ reports are used to define the location of this bias, then the finding of no performance decrement on $\mathrm{BH}+$ trials would follow directly. Events passing through this channel presumably elicit responses with the same latency independently of the number of channels. Increasing decrement as a function of $\mathrm{SU}$ on $\mathrm{BH}-$ trials would result from the channel bias having to pass through more channels, on the average, with increasing $\mathrm{SU}$. On the other hand, the lack of performance decrement across SU conditions is somewhat more difficult to deduce from response conflict models because of the assumed interaction among response tendencies.

The present findings indicate that S's behavior in a sensorimotor task is not simply determined by the structural properties of the stimulus sequence. Rather, it would appear that the role of propositional control over behavior is as operative in these tasks as it is in tasks involving the more complex verbal response system (Dulany, 1962; DeNike, 1964; Spielberger, Bernstein \& Ratliff, in press)。

\section{References}

Adams, J. A. Test of the hypothesis of psychological refractory period. J. exp. Psychol., 1962, 64, 280-287.

Berlyne, D. C. Uncertainty and conflict: A point of contact between information-theory and behavior-theory concepts. Psychol. Rev., 1957, 64, 329-339.

Brainard, R. W., Irby, T. S., Fitts, P. M., \& Alluisi, E. A. Some variables influencing the rate of gain of information. $J$. exp. Psychol., 1962, 63, 321-329.

Broadbent, D. E. A mechanical model for human attention and immediate memory. Psychol. Rev., 1957, 64, 205-215.

DeNike, D. The temporal relationship between awareness and performance in verbal conditioning. J.exp. Psychol., 1964, 521-529.

Dulany, D. E. The place of hypotheses and intentions: An analysis of verbal control in verbal conditioning. In C.W. Eriksen (Ed.), Behavior and awareness: A symposium of research. Durham: Duke University Press, 1962. Pp.102-139.

Hyman, R. Stimulus information as a determinant of choice reaction time. J. exp. Psychol., 1953, 45, 188-196.

Posner, M. I. Information reduction in the analysis of sequential tasks. Psychol. Rev., 1964, 71, 491-504.

Spielberger, C, D., Bernstein, I. H., \& Ratliff, R. C. The information and incentive value of the reinforcing stimulus in verbal conditioning. J. exp. Psychol., in press.

\section{Note}

1. Supported by a PHS research grant $M H-11173-01$ and a grant from the Organized Research Fund, Department of Psychology, Arlington State College, to the senior author. A version of this paper was presented at the 1965 convention of the Midwestern Psychological Association. The authors wish to express their appreciation to Mr. David Phillips and $\mathrm{Mr}$. Donald Schurman for their help in designing and constructing the equipment. 